\title{
Responsiveness of the health system towards patients admitted to west of Iran hospitals
}

\author{
Parastoo Baharvand ${ }^{1}$
}

\begin{abstract}
Objective: Responsiveness refers to non-clinical aspects of the health system and responds to this question that whether health system is responsive to rightful expectations of people. This study aimed to assess the responsiveness of the health system towards patients admitted to hospitals in Khorramabad city in 2017.

Methods: This cross-sectional study was conducted on 700 patients hospitalized in hospitals affiliated to Lorestan University of Medical Sciences in Khorramabad, 2017, who were included into the study using multi stage method. Data collection was performed using valid questionnaire that designed by the World Health Organization (WHO) for measurement of responsiveness. Data were entered into SPSS 22 software and analyzed using descriptive and analytical statistics.

Results: In this study, the highest responsiveness was related to social support networks dimension with a mean score of $3.95 \pm 0.92$ and the least responsiveness was related to choice of therapist $(2.70 \pm 0.33)$ and autonomy $(2.81 \pm .0 .71)$ dimensions. According to the viewpoint of patients the most important dimensions were prompt attention (41\%) and dignity (28\%).

Conclusion: According to the results of this study, it seems logical and necessary to take steps to improve the health system's responsiveness for patient care by paying pay more attention to patients' rights, in particular, regarding the provision of conditions and facilities for choosing a health provider and considering their autonomy.
\end{abstract}

Keywords: responsiveness, health system, questionnaire, hospital

\section{INTRODUCTION}

The mission of each health system is to preserve and improve the health status at the societal level. In other words, the basis for the formation of each health system is to meet the needs of the people of the society and the main goal of the health system is to meet such needs that is called responsiveness by WHO (1). Responsiveness is one of the key issues of any health care system and is an important issue for policy makers and health managers. Responsiveness is associated with patient consent (2). Responsiveness has a special concept in the health system and includes care providing methods and also non-clinical aspects of service delivery. Therefore, it does not include categories such as the effectiveness of surgical procedures, drugs, etc. (3). Responsiveness is one of the goals of the health system $(4,5)$. In World Health Report in 2000, the World Health Organization (WHO) released a worldwide ranking of 191 countries in the health system, with the United States ranked $1^{\text {st }}$ and Iran ranked $100^{\text {th }}(6)$. WHO's framework of responsibility includes:

Dignity, Autonomy, Confidentiality, Prompt attention, Access to social support network, Choice of health provider, patient communication, consideration of patients' viewpoint and cooperation, and basic amenities (7). This responsiveness is different from the concept expected in other organizations and social institutions. Responsiveness in the public sector is called Accountability. And needs a proper accountability system. Government agencies are created by and for the people. So they must be accountable (). In the health sector, responsiveness is used as another concept. In Iran, the Ministry of Health considers this issue in the third, fourth, and fifth health plans of the country development (8). Different aspects of responsiveness in health sector emphasize the human dimensions of health services. The first aspect of human behavior is attention to dignity and humanity of the patient. This concept emphasizes obtaining the

1 Assistant professor, Department of Social Medicine, School of Medicine, Lorestan
University of Medical Sciences, Khorramabad, Iran

Received: 22 Mar 2018, Accepted: 18 Apr 2018
Correspondence: Parastoo Baharvand

Assistant professor, Department of Social Medicine, School of Medicine, Lorestan University of Medical Sciences, Khorramabad, Iran

(C) 2019 by the authors; licensee Modestum Ltd., UK. This article is an open access article distributed under the terms and conditions of the Creative Commons Attribution License (http://creativecommons.org/licenses/by/4.0/). 
trust of the patient and his companions and good manners with them (9). Another aspect of the issues raised as responsiveness is to pay attention to individual's autonomy and to respect his independence and his ability to decide on his own health. Another aspect is the confidentiality of who has access to the patient's personal information and the other is prompt attention in emergency cases (9). Patients expect that, in addition to maintaining their health, the health system treats them with dignity, facilitates their decisions in the care and treatment method, and provide them with clear communication and assurance that their information will stay confidential $(4,10)$. In developed countries, there is evidence that the patients have the highest satisfaction with the health system, when the health caregivers provided them with the information on care and treatment $(11,12)$. In developing countries, on the contrary, it has been observed that most patients tend the caregivers decide about their care and treatment, rather than themselves being involved with treatment and care (13-15). The importance of responsiveness in the health system, beyond being one of the main goals of the WHO in the health system's performance, addresses the legitimate expectations of patients. Also, facilitating the information provision between the health system and individuals is a key component of responsiveness. And it is important to note that the success of any health system depends on the responsiveness of that system to the legitimate expectations of patients (16). This study aimed to evaluate the health system's responsiveness at educational hospitals in Khorramabad; the results of this research can provide information for health managers in order to measure the patients' expectations better.

\section{METHODS}

\section{Study Setting and Sample}

Cross-sectional study was conducted on patients admitted to educational hospitals affiliated to Lorestan University of Medical Sciences in Khorramabad who were selected using multi-stage (stratified-randomized) method from June 2016 to May 2017. The inclusion criteria included age over 16, at least 72 hours admission in wards, and the patient's willingness to participate in the study, and exclusion criteria included hospitalization in the emergency department or ICU, unconsciousness, and psychiatric disorders.

\section{Measurement and Device}

Data collection was performed using the Persian version of the health system responsiveness questionnaire designed by the WHO. (WHO responsiveness Tools). Validity and reliability of this questionnaire have already been approved (18, $17,19$, and 10$)$. In this study, the reliability of the questionnaire was also obtained (0.85) using test-retest method. Cronbach's alpha, the dimensions of the questionnaire were also between $0.62 \%$ and $0.84 \%$. The questionnaire consisted of two parts. The first part includes patients' information such as gender, age, level of education, place of residence, and duration of hospitalization and the second part of the questionnaire consists of 33 questions in 8 dimensions: 1- Dignity (5 questions), 2- Autonomy (4 questions), 3- Prompt attention (6 questions), 4- Communication (5 questions), Confidentiality (3 questions), 6 - Social support (3 questions), 7- Basic amenities (4 questions), and Choice of provider (2 questions). Questions are scaled from a score of 1 to 10 . The questionnaire was completed in a self-contained manner, and the questionnaires were filled out by the interviewers for the illiterate people. In order to obtain reliable information, the questioner was trained for communication techniques, neutral interview and observance, adherence to the content of the questionnaire's text, and maintaining its authenticity.

\section{Statistical Methods}

Data analysis was performed by SPSS ver.22 using descriptive statistics (mean, standard deviation and frequency) and analytical statistics ( $t$ test, one way analysis of variance, Pearson coefficient ), and $P<0.05$ was considered significant.

\section{RESULTS}

In this study, 700 patients were studied. The mean age of the patients was $45.5 \pm 8.9$ with the minimum and maximum age of 17 and 85 years, respectively. Male, illiterate and urban subjects made up $51.7 \%, 23.3 \%$ and $59.9 \%$ of the participants, respectively. The average number of days of admission was $8.5 \pm 3.6$ days. The socio-demographic characteristics of patients are illustrated in Table 1. 
Table 1: Frequency of demographic characteristics in patients. (p: 11)

\begin{tabular}{ccc}
\hline Variables & No. (\%) & Cumulative Percentage \\
\hline Age & $49(7)$ & 7.0 \\
\hline$<20$ Years & $181(25.8)$ & 32.8 \\
\hline $21-35$ Years & 62.4 & 84.0 \\
\hline $36-50$ Years & $207(29.6)$ & 100.0 \\
\hline $51-65$ Years & $151(21.6)$ & 23.3 \\
\hline$>65$ Years & $112(16)$ & 53.7 \\
\hline Educational Level & $163(23.3)$ & 66.1 \\
\hline Illiterate & $213(30.4)$ & 87.7 \\
\hline Secondary school & $87(12.4)$ & 100 \\
\hline High school & $151(21.6)$ & \\
\hline Diploma & $86(12.3)$ & 59.9 \\
\hline College degree & $419(59.9)$ & 100.0 \\
\hline Place of Residence & $281(40.1)$ & \\
\hline Urban & $338(48.3)$ & 10.3 \\
\hline Rural residents & $362(51.7)$ & 100.0 \\
\hline Sex & $8.5 \pm 3.6$ & \\
\hline Male & \\
\hline
\end{tabular}

Table 2: Mean Score of different dimensions of responsiveness from patients' perspective ( $p$ : 11)

\begin{tabular}{lc}
\hline Dimensions of Responsiveness & Mean \pm SD \\
\hline Choice of provider & $2.70 \pm .0 .53$ \\
\hline Autonomy & $2.81 \pm .0 .71$ \\
\hline Prompt attention & $3.1 \pm .0 .85$ \\
\hline Basic amenities & $2.95 \pm .0 .78$ \\
\hline Dignity & $3.7 \pm .0 .98$ \\
\hline Social support & $3.95 \pm .0 .92$ \\
\hline Confidentiality & $3.87 \pm .0 .75$ \\
\hline Communication & $3.5 \pm .0 .82$ \\
\hline Autonomy & $3.75 \pm .1 .02$ \\
\hline
\end{tabular}

Table 3: Mean score of responsiveness and its different dimensions based on level of educational

\begin{tabular}{|c|c|c|c|c|c|c|c|c|c|}
\hline Education & $\begin{array}{l}\text { Choice of } \\
\text { Provider }\end{array}$ & Autonomy & $\begin{array}{c}\text { Prompt } \\
\text { Attention }\end{array}$ & $\begin{array}{c}\text { Basic } \\
\text { Amenities }\end{array}$ & Dignity & $\begin{array}{c}\text { Social } \\
\text { Support }\end{array}$ & Confidentiality & Communication & Total Score \\
\hline & Mean \pm SD & Mean \pm SD & Mean \pm SD & Mean \pm SD & Mean \pm SD & Mean \pm SD & Mean \pm SD & Mean \pm SD & Mean \pm SD \\
\hline Illiterate & $2.63 \pm .099$ & $3.67 \pm .0 .75$ & $2.16 \pm 0.71$ & $2.59 \pm 0.67$ & $3.93 \pm 1.09$ & $4.1 \pm 1.1$ & 3.48. \pm 0.83 & $3.01 \pm 0.80$. & $3.85 . \pm 0.64$ \\
\hline $\begin{array}{l}\text { Secondary } \\
\text { School }\end{array}$ & 2.58. \pm .077 & $3.64 \pm 0.74$ & $2.75 \pm 0.68$ & $2.70 \pm 0.71$ & $3.65 \pm 1.09$ & $3.74 \pm 1.2$ & 3.37. \pm 0.69 . & 3.43. \pm 0.85 & $3.79 \pm 0.57$ \\
\hline High School & $2.48 \pm .098$ & $2.86 \pm 0.68$ & $3.15 \pm 0.84$ & $2.74 \pm 0.70$ & $3.59 \pm 0.98$ & $3.59 \pm 0.90$ & 3.52. \pm 0.78 & 3.12. \pm 1.04 . & $3.32 \pm 0.98$ \\
\hline Diploma & $2.73 \pm .084$ & $2.45 \pm 0.52$ & 3.64. \pm 0.76 & $2.90 \pm 0.71$ & $3.38 \pm 0.88$ & $3.8 \pm 1.1$ & $3.69 . \pm 1.01$ & $3.33 \pm 0.73$ & 3.18. \pm 1.09 \\
\hline College Degree & $2.89 \pm .0 .91$ & $2.23 \pm .0 .65$ & $3.05 \pm .0 .81$ & $2.94 \pm .1 .13$ & $3.11 \pm .0 .96$ & $4.28 \pm .1 .22$ & 3.32. \pm .0 .89 & 3.35. \pm .1 .01 . & 2.97. \pm 0.56 \\
\hline$P$ value & 0.022 & 0.001 & 0.001 & 0.34 & 0.11 & 0.06 & 0.42 & 0.13 & 0.001 \\
\hline
\end{tabular}

According to Table 2, the highest mean score of responsiveness was related to social support (3.95 \pm 0.92$)$ and confidentiality $(3.87 \pm 0.75)$ dimensions, respectively, while the minimum mean scores were related to the choice of provider $(2.70 \pm 0.53)$ and autonomy $(81.8 \pm 0.71)$, respectively.

As shown in Table 4, the average responsiveness score and its different dimensions vary between groups with different levels of education. One-way ANOVA was used to compare the mean scores of responsiveness dimensions and results indicated a significant difference between groups with different levels of education $(P \leq 0.05)$. Post-hoc Tukey test showed there was a difference between groups with higher education level (diploma and university education) and lower-educated groups (illiterate subjects and those with middle school education) in the autonomy dimension. There was also a difference between the mean scores obtained by the two groups of graduates with illiterate people and finally there was a difference between the overall responsiveness score among those with university education and those with lower education (illiterate subjects and those with middle school education) in the prompt attention dimension $(P<0.05)$. 
Table 4: Mean score of responsiveness and its different dimensions based on place of residence

\begin{tabular}{|c|c|c|c|c|c|c|c|c|c|}
\hline $\begin{array}{l}\begin{array}{l}\text { Place of } \\
\text { residence }\end{array} \\
\end{array}$ & $\begin{array}{l}\text { Choice of } \\
\text { Provider }\end{array}$ & Autonomy & $\begin{array}{c}\text { Prompt } \\
\text { Attention }\end{array}$ & $\begin{array}{c}\text { Basic } \\
\text { Amenities }\end{array}$ & Dignity & $\begin{array}{c}\text { Social } \\
\text { Support } \\
\end{array}$ & Confidentiality & Communication & Total Score \\
\hline & Mean \pm SD & Mean \pm SD & Mean \pm SD & Mean \pm SD & Mean \pm SD & Mean \pm SD & Mean \pm SD & Mean \pm SD & Mean \pm SD \\
\hline Urban & $2.13 \pm 0.48$ & $2.22 \pm 0.51$ & $2.19 \pm 0.57$ & $2.59 \pm 0.67$ & $3.13 \pm 1.01$ & $4.1 \pm 1.1$ & $3.18 \pm 0.83$ & $2.91 \pm 0.58$ & $2.81 \pm 0.63$ \\
\hline $\begin{array}{l}\text { Rural } \\
\text { Residents }\end{array}$ & $3.47 \pm 0.77$ & $3.39 \pm 0.65$ & $3.43 \pm 0.71$ & $2.70 \pm 0.71$ & $3.80 \pm 1.04$ & $3.74 \pm 1.2$ & $3.87 \pm 0.69$ & $4.22 \pm 0.75$ & $4.19 \pm 0.74$ \\
\hline$P$ value & 0.001 & 0.001 & 0.001 & 0.35 & 0.41 & 0.06 & 0.19 & 0.001 & 0.001 \\
\hline
\end{tabular}

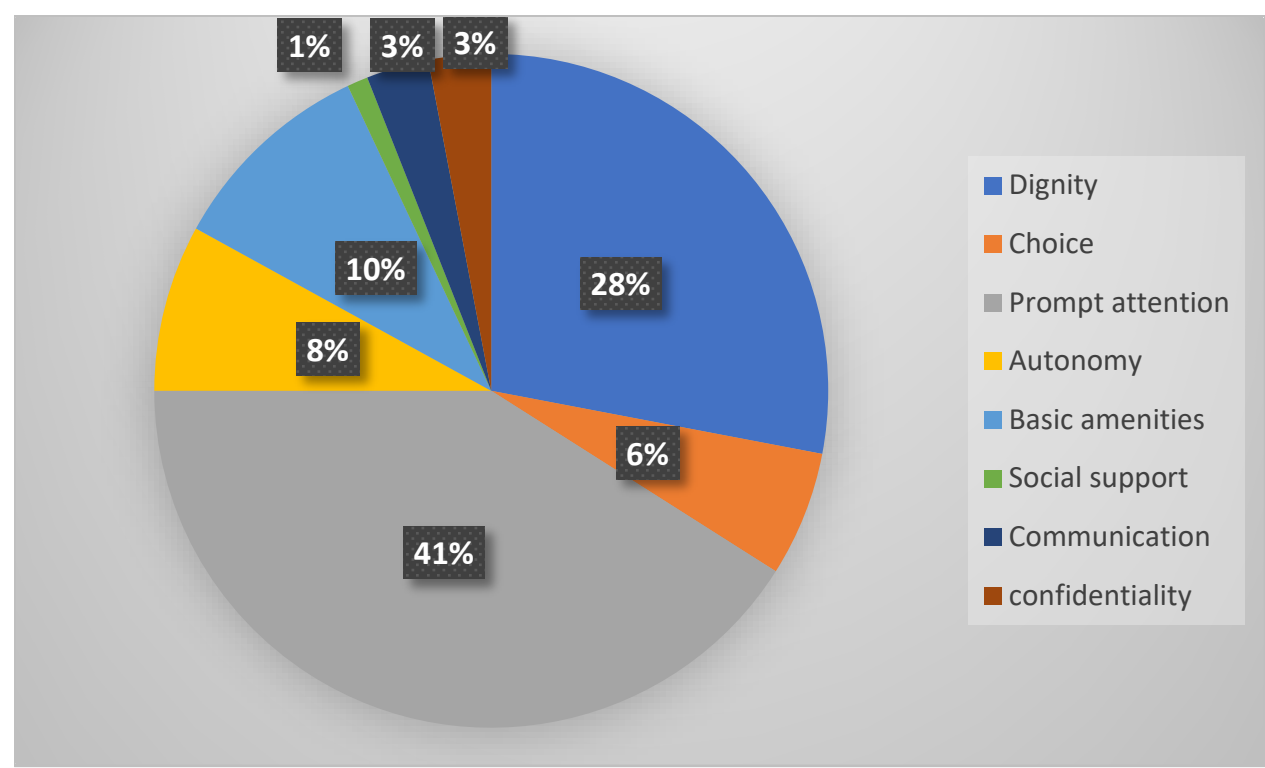

Figure 1: Domains of responsiveness ranked based on their importance from patient's view

Comparison of mean scores of responsiveness dimensions using T-test showed statistically significant difference between two groups living in urban and rural areas $(P<0.05)$. Form the viewpoint of urban residents compared with rural residents, mean scores of responsiveness were lower in the autonomy, prompt attention, choice of provider, and communication dimensions, as well as the overall score of the questionnaire $(P<0.05)$.

As noted in Figure 1, prompt attention (41\%, Cl 95\%: 35.4\%-46.6\%) and dignity (28\%, Cl 95\%: 23.2\%-32.8\%) were the most important dimensions from the patients' perspective.

There was a significant and inverse relationship between the total responsiveness score and the duration of admission $(P<0.05, r=-0.48)$ and increased hospital stay decreased the responsiveness score. Comparison of mean scores of responsiveness dimensions between the two sex groups did not show a statistically significant difference $(P>0.05)$.

\section{DISCUSSION}

The main objective of this study was to assess the responsiveness of educational hospitals to care for patients. Mean score of responsiveness from the patient's point of view was $3.75 \pm 1.02$, similar to those in Turkey (9), China (20) and Iran [Ebrahimpour (17) and Zarei (18)]. In assessment of the questionnaire dimensions, the highest mean score was related to the dimensions of social support and confidentiality and the least was related to the dimensions of choice of provider and autonomy.

Nejru et al showed regarding the choice of provider dimension that the majority of users (71\%) believed that they did not have a choice about the care provider (21).

In the study by Javadi et al. on non-medical aspects of health services in patients admitted to Isfahan hospitals, patients described the weakest points of the medical centers as the choice of therapist and nurses and basic amenities (22).

In the study by Ristea, patients gave the lowest points to the "right to choose therapist". Nurses also had a negative view on this issue and it was considered as the second weak point (23). In Ibrahimpur's study (17), patients evaluated the right to choose a therapist lower in public hospitals rather than private hospitals. A study by Bramesfeld et al., entitled "How does mental health care perform in respect of service users' expectations" in Germany (24) and in the study by Peltzer, entitled "Patient experiences and health systems responsiveness among older adults in South Africa" (25), the 
right to choose therapist was scored the least by patients. The results of our study are also consistent with the studies mentioned above.

This finding is not far from the mind in our country, as according to another study, free choice of therapist or hospital for treatment is unusual in many countries; even more Europeans are not used to choose provider freely. One reason for this seems to be the lack of confidence in their ability to make good choices and inadequate knowledge to choose (13).

Choosing a therapist is an important issue that has a particular importance and challenge in the health system (26), as in studying responsiveness in 8 European countries, the majority of people in 7 countries assessed the right to choose a therapist low and attributed this to insufficient knowledge for choice; among the countries studied, only Swedish respondents had no problem with this (27).

Independence and autonomy, after the choice of provider, were the lowest. This finding is consistent with those of Javadi (22), Mousavi (28), Ebrahimpour (17), Sajjadi (29) in Iran, and Meleslam studies (30) in Egypt and Kowal in China (20). The degree of involvement and cooperation of the patient in health issues is a topic that varies according to the common medical culture in different regions. For example, the medical model in a paternalist culture is that the doctor and the patient agree that the decision on treatment is the responsibility of the physician. When the patient participates in choosing the therapeutic program, this will not only make her/him accept and adapt to the therapeutic methods, but will also improve the patient's and doctor's interactions and satisfaction.

After the dimensions of the right to choose the therapist and autonomy, the basic amenities had the lowest mean. In the studies by Zarei et al. (18) and Ebrahimpour (17) in Iran, and Bramesfeld (24), Peltzer (25), and Kowal (20), responsiveness score was reported high in the basic amenities dimension. In the study of responsiveness assessment at Turkish hospitals conducted by Ugurluoglu, basic amenities were also reported high (9). In this study, contrary to the above mentioned studies, mean score of basic amenities was reported to be consistent with the study of Javadi (22), Fazaeli (31), and Ristea (23). Since the quality and quantity of hospital facilities have an undeniable effect on patients' comfort, improvement of the quality and quantity of hotel services and physical facilities seems reasonable. In this study, the highest mean score was related to social support dimensions, which is consistent with the studies of Javadi (22) and Ugurluoglu (9).

Since access to social support is a very important factor in the process of treatment and disease improvement, this finding can be a desirable outcome.

After social support, the highest mean score was related to confidentiality and dignity. In the study by Bramsfield and colleagues, participants described the best-performing dimension of healthcare responsiveness as confidentiality and secrecy (24); Plutz also showed the highest score of responsiveness, according to patients, as respecting the patients and their privacy during physical examination (24). In Ugurluoglu's study, the score of confidentiality dimension was reported high (9). In the study of Rashidian et al. (19) and Mohammadi's (10) study, the best performance of responsiveness was related to the dimensions of secrecy and respect for the patients' dignity.

In this study, there was a significant correlation between different age groups and different dimensions of responsiveness in two dimensions of social support and dignity.

Also, in this study, there was a relationship between the place of residence and the level of education with different dimensions of responsiveness. In urban residents and those with higher education, mean scores were lower in some dimensions, which was consistent with the study (31). Given the fact that the lower knowledge of one's rights brings lower expectation of services, it can be concluded that if people living in urban areas or those with higher education considered hospitals to be less responsive in some aspects, it was because of their awareness of their rights that increased their expectation of services and, as a result, reduced their satisfaction. The difference between groups can also be related to different perceptions and expectations of individuals.

The findings of this study did not show a significant relationship between sex and dimensions of responsiveness, which is consistent with the study of Fazaeli and colleagues (31) and Rashidian (19), and contrary to the study of Mohammadi (10) and Sajjadi (29). In this study, there was an inverse relationship between the duration of hospitalization and hospital's responsiveness, which is consistent with Zare's study (18). This finding can be justified by this fact that longer admission will make the patient feel that their disease is serious, which causes them to be worried and creates a negative view on hospital services and medical staff.

In this study, the most important aspects of responsiveness, according to patients, were prompt attention and dignity. Although the importance of different dimensions of responsiveness for patients is dissimilar in different societies, but the dimensions of prompt attention and dignity are considered more important than other dimensions in studies, including in the study by Valentine et al (3), Kowal et al (20) and Liabsuetraku et al. (32) that described these two 
dimensions as the most important aspects of the health system's responsiveness, according to patients. Patient satisfaction would be provided by providing patient care services along with immediate action and reducing the waiting time, while it prevents the formation of negative and pessimistic thoughts about the health service delivery system.

The present study also had limitations. The research was only restricted to educational hospitals. Secondly, these subjects included hospitalized patients and those who received outpatient services were not enrolled in the study. It is recommended that these cases be studied in the future studies.

\section{CONCLUSION}

In this study, the choice of provider and autonomy dimensions were determined as the priorities. It is suggested that, in order to improve the responsiveness of the health system, policies and procedures should be designed using international experiences and local point of views, while more attention should be paid to patients' rights and by giving them information, their further participation in decision making for treatment will be provided. Also, the focus of health managers and policy makers on training staff regarding responsiveness, improving service quality, and allocating resources properly will improve responsiveness in the health system.

\section{REFERENCES}

1. Malhotra C, Do YK. Socio-economic disparities in health system responsiveness in India. Health Policy Plan. 2013;28(2):197-205. https://doi.org/10.1093/heapol/czs051 PMid:22709921 PMCid:PMC3584994

2. Messina DJ, Scotti DJ, Ganey R, Zipp GP, The relationship between patient satisfaction and inpatient admissions across teaching and nonteaching hospitals. Journal of healthcare management/American College of Healthcare Executives. 2009;54(3):177.

3. Valentine N, Darby C, Bonsel GJ. Which aspects of non-clinical quality of care are most important? Results from WHO's general population surveys of "health systems responsiveness" in 41 countries. Social Science \& Medicine. 2008;66(9):1939-50. https://doi.org/10.1016/j.socscimed.2007.12.002 PMid:18313822

4. De Silva A. A framework for measuring responsiveness. Geneva: World Health Organization, unpublished document, GPE Discussion Paper Series: No. 34. 2002.

5. Murray CJ, Frenk J, A framework for assessing the performance of health systems. Bulletin of the World Health Organization. 2000:78(6):717-31. PMid:10916909 PMCid:PMC2560787

6. Reinhardt UE, Cheng T m, the world health report 2000-Health systems: improving performance. Bulletin of the World Health Organization. 2:1064: (8)78.

7. De Silva A. A Framework for Measuring Responsiveness. GPE Discussion Paper Series No. 32 [Online]. 1997; Retrieved from http://www.who.int/healthinfo/paper32.pdf

8. Ministry of Health. Third and fourth development plans [Online]. 2010; Retrieved from http://hamahangi.behdasht.gov.ir/index.aspx?siteid=126\&pageid=955

9. Ugurluoglu O, Celik Y. How responsive Turkish health care system is to its citizens: the views of hospital managers. Journal of Medical Systems. 2006;30(6):421-8. https://doi.org/10.1007/s10916-005-9006-8

10. Mohammadi A, Kamali K. Patients' Perspectives on Responsiveness in Outpatient Clinics of Hospitals at Zanjan University of Medical Sciences. Preventive Care in Nursing \& Midwifery Journal (PCNM). 2015;5(1).

11. Aharony L, Strasser S. Patient satisfaction: what we know about and we still need to explore. Medical Care Review 1993;50:49-79. https://doi.org/10.1177/002570879305000104 PMid:10125117

12. Ware JE, Snyder MK, Wright WR, Davies AR. Defining and measuring patient satisfaction with medical care.Evaluation and Program Planning. 1983;6:247-263. https://doi.org/10.1016/0149-7189(83)90005-8

13. Wouters A. Essential national health research in developing countries: health care financing and the quality of care. International Journal of Health Planning and Management. 1991;6:253-271. https://doi.org/10.1002/hpm.4740060403

14. McPake B. User charges for health services in developing countries: a review of the economic literature. Social and Science and Medicine. 1993;36:1397-1405. https://doi.org/10.1016/0277-9536(93)90382-E

15. Gilson L, Alilio M, Heggenhougen K. Community satisfaction with primary health care services: an evaluation undertaken in the Morogoro region of Tanzania. Social Science and Medicine. 1994;39:767-780.

16. Gakidou EE, Frenk J, Murray CJL. Measuring preferences on health system performance assessment. Geneva, World Health Organization, 2000 (Global Programme on Evidence for Health Policy Discussion paper No. 20) 
17. Ebrahimipour H, Najjar A, Jahani AK, Pourtaleb A, Javadi M, Rezazadeh A, et al. Health system responsiveness: a case study of general hospitals in Iran. International journal of Health Policy and Management. 2013;1(1):85-90. https://doi.org/10.15171/ijhpm.2013.13

18. Zarei E, Daneshkohan A, Khodakarim S, Shamsdini Lori A, Ahmadi Kashkoli S. Hospitals' Responsiveness from the patient's perspective: A cross-sectional Study in Tehran, Iran. Pejouhandeh 2016;21(2):99-10.

19. Rashidian A, Kavosi Z, Majdzadeh R, Pourreza A, Pourmalek F, Arab M, et al. Assessing health system responsiveness: a household survey in 17th District of Tehran. Iranian Red Crescent Medical Journal. 2011;13(5):302-8. PMid:22737485 PMCid:PMC3371967

20. Kowal P, Naidoo N, Williams SR, Chatterji S. Performance of the health system in China and Asia as measured by responsiveness. Health. 2011;3(10):638-46. https://doi.org/10.4236/health.2011.310108

21. Njeru MK, Blystad A, Nyamongo IK, Fylkesnes K. A critical assessment of the WHO responsiveness tool: lessons from voluntary HIV testing and counseling services in Kenya. BMC Health Serv Res. 2009;9:243. https://doi.org/10.1186/1472-6963-9-243 PMid:20028540 PMCid:PMC2811110

22. Javadi M, Yaghoobi M, Raiesi A, Mandegar HA, Ayoobian A. A Study of Non-Medical Aspects of Health Services Provided to Patients in Selected Hospitals of Isfahan: Responsiveness. Health Information Management. 2011;8(5):709-17.

23. Ristea AL, Stegaroiu I, Franc VI, Dinu V. Responsiveness of Health Systems: a Barometer of the Quality of Health Services. j 2009;11(26):277-87.

24. Bramesfeld A, Wedegärtner F, Elgeti H, Bisson S. How does mental health care perform in respect to service users 'expectations? Evaluating inpatient and outpatient care in Germany with the WHO responsiveness concept. BMC Health Services Research. 2007;7(1):79-99. https://doi.org/10.1186/1472-6963-7-99 PMid:17605786 PMCid:PMC1931438

25. Peltzer K, Phaswana-Mafuya N. Patient experiences and health system responsiveness among older adults in South Africa. Global Health Action. 2012;5(2):1-11. https://doi.org/10.3402/gha.v5i0.18545

26. Fotaki M, Roland M, Boyd A, Mc Donald R, Scheaff $R$, Smith $L$.What benefits will choice bring to patients? Literature review and assessment of implications. Journal of Health Services Research \& Policy. 2008; 13(3):17884. https://doi.org/10.1258/jhsrp.2008.00716

27. Coulter A, Jenkinson C. European patients' views on the responsiveness of health systems and healthcare providers. The European Journal of Public Health. 2005;15:355-60. https://doi.org/10.1093/eurpub/cki004 PMid:15975955

28. Mousavi M, Erfanian Taghvaee M, Salehi M. Health System's Responsiveness of Inpatients: Hospitals of Iran. Global Journal of Health Science. 2015;7(7):106-113.

29. Sajjadi F, Moradi-Lakeh M, Nojomi M, Baradaran HR, Azizi F. Health system responsiveness for outpatient care in people with diabetes Mellitus in Tehran. Medical Journal of the Islamic Republic of Iran 2015; $29(1): 1136$-49

30. Mosallam R, Aly MM, Moharram AM. Responsiveness of the health insurance and private systems in Alexandria, Egypt. The Journal of the Egyptian Public Health Association. 2013; 88(1):46-51. https://doi.org/10.1097/01.EPX.0000427042.54093.c4 PMid:23528532

31. Fazaeli S, Hashemi S, Ebrahimipour H, Banikazemi H, Yousefi M. Importance of health System responsiveness in a high and low income areas in Mashhad, Iran: A Household surve. Journal of the Iranian Institute for Health Sciences Research. 2016;4(15):153-162.

32. Liabsuetraku T, Petmanee P, Sanguanchua $S$, Oumudee N. Health system responsiveness for delivery care in Southern Thailand. Int J Qual Health Care. 2012;24(4):169-75. https://doi.org/10.1093/intqhc/mzr085 PMid:22215759

$\diamond \diamond \diamond \diamond \diamond \diamond \diamond$

http://www.ejgm.co.uk 